there were no official publications of the Department. The Indian Forester, a monthly magazine, started in 1885 and still issued, was a private departmental publication.

As research work progressed, it gradually became obvious that some decentralization would be necessary ; for example, one or more provinces might have a major sylvicultural problem requiring study by the sylvicultural research officer. Even with the assistance provided at the Institute, it was not possible to answer all calls. The selection and appointment of local research officers in the provinces which required them was sanctioned, and thus came into being the local research, sylvicultural, forest entomologist, and utilization officers, and, as important as any, the provincial conservator of working plans. These officers kept in close touch with Dehra Dun.

Reference was made in the article in Nature on the teak forests of Burma to the great progress made in working the forests under carefully prepared working plans. In India, by the opening of the Second World War, a network of plans for the forest reserves was in force, and many of these had been revised more than once. Since their early and tentative introduction, great advances had been made in the scope and intensity, of management of many of these plans. The one sine qua non of the working plan, if properly prepared, is that all over-felling is permanently checked. Briefly, only the annual yield, that is, the annual increment put on the trees, is cut. In the memorandum on "Post-War Policy in India, 1944", the Inspector General of Forests was able to write on the subject of excess war fellings in the Government reserve forests in India : "Little is required to restore the departure from normal, that is the excess War Fellings; a 40-50 per cent reduction in pre-War yields for a period of five to ten years, may in some cases be necessary. The true position can be determ. ined by the revision of the Working Plans which must, therefore, be accelerated after the War." This is forestry management brought to a high standard of efficiency.

Lastly, since the financial aspect of this great undertaking by Government forms one of its aspects, the following figures speak for themselves :

Revenue in 1868-69 = Rs. 40,38,800 and Surplus Rs. $12,65,467$.

Revenue in 1936-37 = Rs. 4,38,07,019 and Surplus $\begin{array}{ll}\text { (last year before } & \text { Rs. 1,53,58,194. }\end{array}$ separation of Burma)

In addition, forest produce to the value of Rs. $84,14,946$ was given away free or at reduced rates during 1936-37.

This article has no concern with political questions. It is merely a parting $\longrightarrow$ a farewell to the Indian Forest Service. But in the light of the long experience I have been fortunate to have had in following the progress of the management of the forests of India, and in the study I have been able to make of the history of those forests, it may not be out of place to put out a word of warning. In the case of forests in which the management has been brought along the road to efficiency in working, as understood by the forester using these words, there can be no standing still, no relaxation of supervision, either by the gazetted officer in charge or his chief ranger executive officer, and no delegation of important sylvicultural operations-the constant inspection, for example, of young crops of regeneration until they have passed out of the danger period, the marking of thinnings upon which the whole future of the timber crop depends, and so forth-and equally and all-important, no over-felling, even in an emergency, without a full recognition by the higher authority of its necessity. These are fundamentals. That they have not only been introduced but also maintained in the Government forest estate in India, the Second World War has effectually proved.

I would say this to India and Pakhistan. The British forest officer has built up not only a great legacy which he now makes over to the owner, but he has also brought it to a pitch not, I believe, existent in any comparable area of forest in the world. If it is a proud legacy to leave behind, it is an equally proud one to take over. In the hands of the India and Pakhistan forest officers, the world will watch with interest the further great progress to be achieved, a progress which will afford lessons in tropical forest management for both the executive forester and the research officer, wherever he may be working.

\section{THE WORK OF THE NATIONAL PHYSICAL LABORATORY}

$T$ 'HIS year, 'open days' at the National Physical Laboratory were held on June 21 and 22 . On the first day representatives of industry, including many from organisations having no previous contact with the Laboratory, took this opportunity of seeing the large variety of research and investigational work that is undertaken. On June 22, the occasion of the annual inspection by the Laboratory's General Board, of which the president of the Royal Society is chairman, the visitors included members of the scientific staffs of universities and Government departments.

During the last twelve months the work of the Laboratory has been concentrated so far as possible on those short-term projects of the greatest immediate benefit to industry, although much has also been done during the year on the maintenance of the various national standards and on programmes of fundamental research. No outstanding new developments were on show, but the two hundred and seventy-two scientific exhibits well illustrated the work of the Laboratory's ten divisions, and mention will be made of a few of the more interesting items.

The aerodynamical work on the design of the proposed Severn Suspension Bridge, one of the most interesting exhibits in 1947, has now been transferred to an outstation where scale models are undergoing test in a large wind tunnel. The work of the Aerodynamics Division is largely concerned with problems of high-speed flight, and exhibits in the various tunnels demonstrated the work being done to improve flying performance by the use of specially designed low-drag wings and boundary-layer control by suction or blowing. Researches into problems of stability, control and flutter, increasingly important at high speeds of flight, are being carried on and a model 'xylonite' elastic wing, incorporating the major structural characteristics of a typical aeroplane wing, is used in the study of the twist of a wing caused by a change in distribution of the air loads and its effect on the response of the aeroplane to movement of the ailerons.

The Metrology Division has just completed for the first time since 1932 a comparison of the national copies of the Imperial Standard Yard and the International Metre with their respective principal copies. 
Using specially devised equipment, a new high standard of precision has been attained. Interesting experiments carried out in the United States have established that when gold is irradiated with neutrons in an atomic pile, an isotope of mercury is produced which yields almost ideal monochromatic radiations when electrically excited. It will be possible in due course to propose replacement of the existing material standards of length by definitions in terms of the wave-length of this particular radiation.

Among the new machines made and designed by this Division was shown a floating-micrometer for measuring the diameter and rate of taper of tapered plug screw gauges.

An interesting new development in the Engineering Division is the setting up of a photo-elastic laboratory. The equipment on show included a photo-electric photometer for accurate measurements of the photoelastic patterns. Work on heat transfer in pipes using mercury as the working fluid, started in 1938 but dropped during the war period, has recently been resumed, using an all-steel double-flow heat exchanger.

A strain-operated electronic trigger device designed in the Division was in operation on one of the special machines installed in the Lubrication Laboratory. This device will stop the machine should an increase in frictional force above a critical level indicate that seizure of the bearing under test is imminent. Small variations in strain of a weighbar are converted to voltage changes by an electrical resistance straingauge circuit, and when the strain exceeds a certain predetermined magnitude an electronic trigger is tripped which stops the machine before serious damage occurs. The principles underlying the operation of this device are thought to be applicable to a wide range of machines where the imminence of an unsafe condition may be accompanied by increase of linear strain in one element of the machine.

In the Physics Division the work of the radiology section on the protection of operatives against ionizing radiations and on the measurement of radioactivity is growing in importance with the increased availability of radioactive substances, and a comprehensive range of measuring and standardizing equipment was on show.

During the past year, further progress has been made with the extension of the section dealing with the fundamental work on acoustical standards of measurement. Among other developments which were on view was a room which has been provided for the standardization of microphones and other acoustical instruments. The walls of this room are lined with wedge-shaped absorbent constructions of the type now recognized to be exceptionally effective in suppressing reflected sound, thereby permitting field measurements of the highest accuracy.

A new quartz spectrograph has been installed in the Metallurgy Division, and together with a microphotometer and a precision comparator forms the main equipment of the Spectroscopic Laboratory. One of the interesting activities of this Division is the preparation of new materials and the study of their properties, and attention is now being given to the preparation of the metals vanadium and titanium in a state of high purity. Little is known, so far, of their physical properties and metallurgical behaviour, and this investigation will yield useful fundamental data.

Another notable exhibit was a projection microscope adapted to phase-contrast illumination. In this form high parts of the structure under examination are revealed as bright areas; the low parts dark. Light reflected by the specimen is split into two parts, one being advanced in phase a quarter of a wave-length relative to the other by means of a 'phase-ring' in the objective lens. The two beams are re-combined and the interference between them produces the typical phase-contrast effect. The satisfactory working of the method calls for the replacement of the ordinary disk aperture by one of the ring type. The images are similar to those given by the electron microscope and so help towards appreciating the difference between electron microscope and normal optical microscope images. The phase-contrast microscope is capable of being sensitive to steps of surface-level of about $50 \mathrm{~A}$.

The Electricity Division had on show equipment for extending the range of quartz-controlled oscil. lations to centimetric wave-lengths. A number of stages of frequency multiplication, mixing and amplification are used to obtain sources of oscillation of a power of about 3 watts having frequencies, controlled by the primary standard, of the following values : $33 \cdot 6-36 \cdot 8 \mathrm{Mc} / \mathrm{s}$. in steps of $0.4 \mathrm{Mc} / \mathrm{s}$., $67 \cdot 2-73.6 \mathrm{Mc} / \mathrm{s}$. in steps of $0.8 \mathrm{Mc} / \mathrm{s}$. and $201 \cdot 6-$ $220.8 \mathrm{Mc} / \mathrm{s}$. in steps of $2.4 \mathrm{Mc} / \mathrm{s}$. By using these oscillations and their harmonics up to the order 36 , controlled frequencies are obtained throughout the range 350-8,000 Mc./s. at intervals of 1 per cent. A variable frequency oscillator, monitored by the standard, enables values between the controlled frequencies to be obtained without appreciable loss in accuracy. Two further stages to be added will extend the range to $50,000 \mathrm{Mc} / \mathrm{s}$.

The most obvious application of the equipment is the rapid and precise calibration of wavemeters, but the sources at their fundamental frequencies will also serve for the testing of cables and dielectrics. An application of more fundamental importance may be the study of the radio-frequency spectra of atoms and molecules. The spectra of a number of gases have been examined both in Great Britain and the United States during the last three years, and that of the ammonia molecule, for example, has lines in the neighbourhood of $23,000 \mathrm{Mc} / \mathrm{s}$. the frequencies of which have been measured to a precision of 1 part in $10^{6}$. Such lines can be used as standards of fre. quency, and the possibility of obtaining molecular standards of this kind is exciting considerable scientific interest.

In the High Voltage Laboratory, measurements of the time variation of the light from sparks are being made by means of a photo-multiplier, amplifier and cathode ray oscillograph. The immediate purpose is to provide a spark suitable for shadow photography in the Aerodynamics Division. The effects of electrode material and spark current are being studied and observations are being made on a gas discharge tube suitable for light pulses of 1 micro-second duration.

The Radio Division has developed a cathode ray direction finder for the location of thunderstorms at long ranges. The apparatus exhibited is similar to that used by the Meteorological Office and is of great value in problems such as the routing of aircraft over the Atlantic. A symmetrical arrangement of orthogonal loop aerials is connected to a twin-channel superheterodyne receiver which is tunable over the frequency range $10-30 \mathrm{kc} . \mathrm{s}$., the normal operating frequency being $12.5 \mathrm{kc} . \mathrm{s}$. At this frequency a minimum field-strength of $100 \mu \mathrm{V} . / \mathrm{m}$. (approximately) is required to give a full-scale trace on the cathode 
ray tube ; but for normal operation on atmospherics in Britain, the balanced attenuators incorporated in the equipment are adjusted so that a full-scale trace is given by a field-strength of about $5 \mathrm{mV} . / \mathrm{m}$. Visual observation of the bearing on the cathode ray tube is generally employed, but the equipment can easily be adapted for photographic recording.

The Mathematics Division exhibited the comprehensive range of machinery that it has available for computational work; one room was devoted to an exposition of relaxation methods, which have a wider application than is generally supposed. The Division is also able to offer advice on the application of statistical methods to various research problems.

The work of the Ship Division continues to be directed mainly to satisfying the immediate requirements of the shipbuilding industry for the large volume of new construction both for British and foreign owners. Vibration of ships' hulls is a subject on which much full-scale research has been continued, especially on vessels with long superstructures such as passenger liners, and a vibrograph and accelerometer were shown, together with typical records taken at sea.

Research on the design of ships' propellers is carried on principally in the Lithgow water tunnel, which can be operated at reduced pressures to enable cavitation phenomena to be studied. The tunnel is also equipped with apparatus for the measurement of the thrust delivered by the propeller and the shaft horse-power absorbed.

The Light Division displayed an interferometer capable of comparing the flatness of two surfaces up to $12 \mathrm{in.}$ in diameter. The surfaces need not be in actual contact, although their separation should preferably be small. The observer is able to view, at normal incidence, the interference fringes formed between the surfaces, and means are also provided for recording the fringe system photographically. Examination of the record enables departures from flatness of the order of 0.01 microns to be measured.

Among the exhibits in the Photometry Section of this Division was apparatus for studying the spectral response curves of the various mechanisms in the human retina. The principle is to measure the smallest perceptible intensity of a monochromatic test stimulus applied at a particular point of the retina when the latter is brought into various states of adaptation by exposure to a coloured light-field, which may or may not be of the same wave-length as the test spot.

\section{CALORIMETER BUILDING FOR DOMESTIC HEATING RESEARCH AT THE FUEL RESEARCH STATION, GREENWICH}

\section{By Dr. A. C. MONKHOUSE}

ONox ONSIDERABLE attention has been paid in recent years to the more efficient use of fuel for domestic purposes, and to the development of better appliances for space heating, cooking and water heating. The amount of coal used directly for domestic purposes is about one-quarter of the total coal consumption in Great Britain. If the indirect use as gas, coke and electricity be included, the amount is one-third, or about 60 million tons a year.

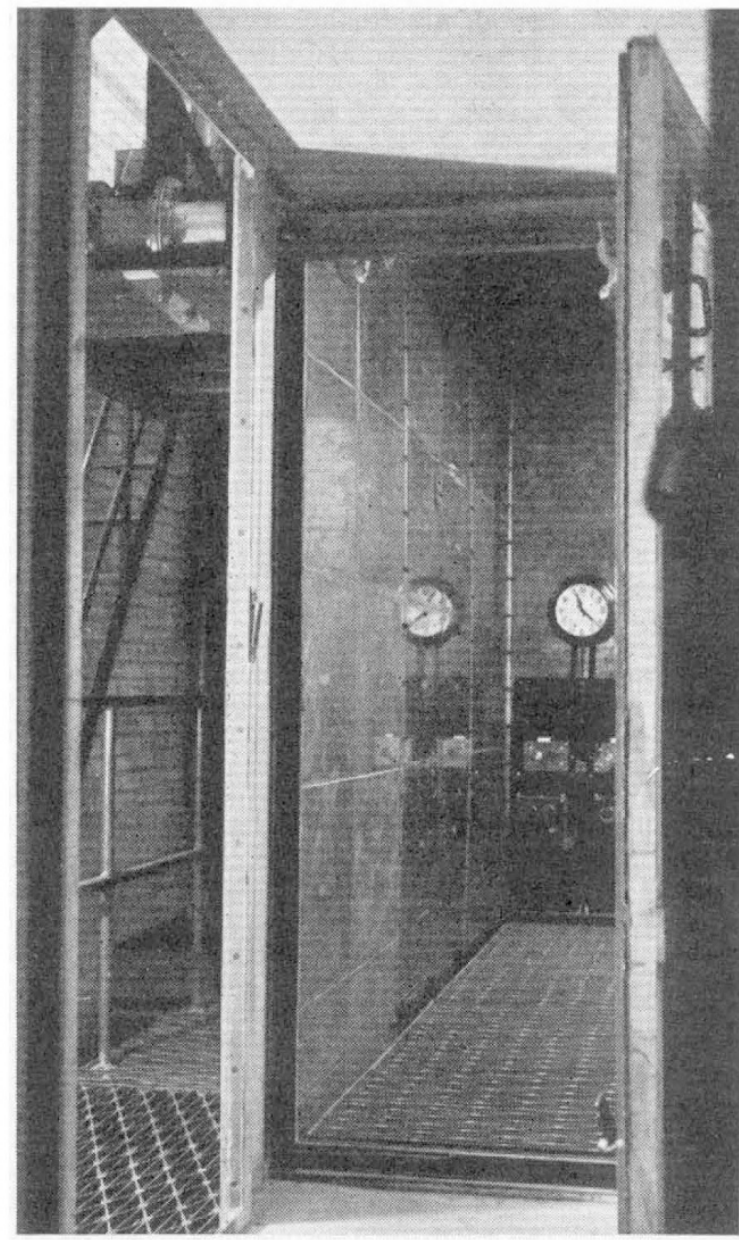

ENTRANCE TO ONE OF THE CALORIMETER ROOMS

Improvements in the domestic use of fuel are of vital importance, therefore, in the economic and social life of the community.

The Fuel Research Station of the Department of Scientific and Industrial Research has in the post-war years, in conjunction with other Government departments, research associations and industry, devised and undertaken tests to determine the performance of the various types of domestic appliances, particu. larly those using solid fuels. These tests involve the measurement of fuel consumption, the amount of heat emitted as radiation and convection, the heat imparted to the water, the loss of potential and sensible heat in the products of combustion, and the quantity of smoke produced. Some measurements, such as those of convection, are with many appliances difficult to determine directly and are usually assessed by a difference figure in the heat balance. To obtain more accurate data of the distribution of heat from an appliance, a special laboratory building has recently been erected at the Fuel Research Station at Greenwich; it was opened for inspection by Sir Edward Appleton on June 30.

The building is a four-story structure occupying a ground area of about $3,000 \mathrm{sq}$. ft. On the first floor are four rooms or cabinets, $12 \mathrm{ft}$. square and $9 \mathrm{ft}$. high, each mounted centrally in a constant temperature chamber $20 \mathrm{ft}$. square and $26 \mathrm{ft} .6 \mathrm{in}$. high. In 